\title{
The Active Management of Postpartum Uterine Atony-A Checklist Based Approach
}

\author{
Rachael Bailey1, Michael R. Foley', Nicole Hall'2, Adiel Fleischer ${ }^{3}$, Mary D'Alton", \\ Gary A. Dildy2, Michael A. Belfort ${ }^{2}$, Gary D. Hankins ${ }^{5}$, Steven L. Clark ${ }^{2}$ \\ ${ }^{1}$ University of Arizona College of Medicine Phoenix, Banner University Medical Center Phoenix, Phoenix, USA \\ ${ }^{2}$ Baylor College of Medicine/Texas Children's Hospital, Houston, USA \\ ${ }^{3}$ Northwell Health-Hofstra School of Medicine, New York, USA \\ ${ }^{4}$ Columbia University College of Physicians and Surgeons, New York Presbyterian Hospital, New York, USA \\ ${ }^{5}$ University of Texas Medical Branch at Galveston, Galveston, USA \\ Email: Rachael.Bailey2@bannerhealth.com
}

How to cite this paper: Bailey, R., Foley, M.R., Hall, N., Fleischer, A., D’Alton, M., Dildy, G.A., Belfort, M.A., Hankins, G.D. and Clark, S.L. (2016) The Active Management of Postpartum Uterine Atony-A Checklist Based Approach. Open Journal of Obstetrics and Gynecology, 6, 646-653.

http://dx.doi.org/10.4236/ojog.2016.611081

Received: August 3, 2016

Accepted: September 25, 2016

Published: September 28, 2016

Copyright $\odot 2016$ by authors and Scientific Research Publishing Inc. This work is licensed under the Creative Commons Attribution International

License (CC BY 4.0).

http://creativecommons.org/licenses/by/4.0/

\begin{abstract}
Uterine atony remains the major cause of postpartum hemorrhage, and of death from postpartum hemorrhage in the United States. While existing guidelines outlining a general approach to postpartum hemorrhage are useful, recent data suggest that greater specificity may be necessary to significantly impact mortality. We present a highly specific and methodical approach to the management of uterine atony, which addresses what we believe to be the most common cause of preventable maternal hemorrhagic death in the US-lack of an intensive, focused approach to atony and perseverance with therapies that are not working. This protocol should result in cessation of hemorrhage by medical or surgical means within 1 hour of diagnosis. We then apply this protocol to a number of illustrative cases of maternal death due to atony. An approach involving the active management of uterine atony may assist clinicians in avoiding severe morbidity and mortality from uterine atony.
\end{abstract}

\section{Keywords}

Postpartum Hemorrhage, Obstetric Hemorrhage, Uterine Atony

Postpartum hemorrhage is a major cause of maternal morbidity and mortality throughout the world [1]-[3]. Despite the widespread availability of potent uterotonic agents and effective surgical techniques for the treatment of uterine atony, this condition also remains both the most common etiology of postpartum hemorrhage and the most common cause of mortality from such bleeding in the US [1] [3]. A number of useful protocols have been developed to guide clinical approaches to the quantification of he- 
morrhage, resource mobilization, fluid and blood replacement and general considerations of available techniques for stopping hemorrhage [3] [4]. However, no evidence exists that such protocols are effective in actually reducing maternal mortality. One recent review of maternal deaths in over one million U.S. births compared the effectiveness of different types of protocols and demonstrated such a general approach to be less effective in preventing death from hemorrhage than were unambiguous checklists narrowly directed at specific clinical practices associated with death due to post-cesarean pulmonary embolism and hypertensive crisis [1] [3]. These and other investigators have observed that adverse outcomes resulting from postpartum hemorrhage are often primarily related to inadequately aggressive intervention and delay in utilizing available techniques for resolving hemorrhage due to uterine atony [3] [5] [6]. These authors postulated that development of a highly specific, checklist-driven protocol for the medical management of postpartum uterine atony may be helpful in avoiding maternal deaths resulting from this condition [3].

We present here such a protocol for the active management of postpartum uterine atony [Figure 1]. It is intended to be initiated upon the diagnosis of postpartum uterine atony, utilizes widely available drugs and medical devices, and is intended to ensure the resolution of all serious atony-related hemorrhage within an hour by either medical or surgical means.

Following the development of this protocol, we extracted specific clinical data from the medical records of 10 women who exsanguinated from uterine atony. These charts originated in quality-related reviews performed by the authors in several states between 2003 and 2011. In all cases a detailed review of the medical records revealed uterine atony as the exclusive cause of hemorrhage that led to death. Our goal was to address 3 questions:

1) Had this protocol been applied, would the patients have received additional doses of drugs directed at the resolution of uterine atony in a shorter time frame than occurred in actual clinical practice?

2) Had this protocol been applied, would the patients have received earlier transfusion?

3) Had the protocol been applied, would the patients have come to operative intervention for definitive treatment prior to the time of actual cardiac arrest?

For each patient, a timeline was constructed detailing the times of administration of various drugs following the diagnosis of uterine atony, the initiation of transfusion, the onset of severe tachycardia ( $>120 \mathrm{bpm})$, the initiation of laparotomy (where applicable) and the time of cardiac arrest [Table 1]. A diagnosis of atony was assumed at the time of the order for, or actual administration of the first medication directed at resolution of atony (other than oxytocin), unless the time of diagnosis was clearly charted as a separate observation. We then superimposed upon this timeline an alternative timeline directed by the checklist. For purposes of this analysis, we assumed a 20 minute interval between the time a laparotomy was called for and actually initiated in patients who had been bleeding and treated for at least 40 minutes with 3 different agents prior to the decision for laparotomy. 


\section{UTERINE ATONY CHECKLIST}

This protocol is to be accompanied by general measures for summoning assistance and instituting supportive care, fluid and blood product infusion. If any drugs used to treat atony are contraindicated in a specific patient, advance to the next step in the protocol. For a diagnosis other than atony, institute condition-specific treatment.

Time

$\operatorname{EBL}(\max )^{*}$

Blood pressure*

Pulse*

\section{Atony Diagnosed;}

$\mathrm{EBL}<500 \mathrm{cc}$

1. Bimanual compression

2. Oxytocin $40 \mathrm{u}$ in $1 \mathrm{~L} N \mathrm{NS}$ wide open

3. Call for drug 1(15 methyl PGF2 $\alpha$ or methergine)

\section{Wait 5 minutes}

\section{Atony Diagnosed;}

$\mathrm{EBL}>500 \mathrm{cc} * *$

1. Continue bimanual compression

2. Administer drug 1

3. Call for drug 2 ( 15 methyl PGF2 $\alpha$ or methergine)

4. Type and cross

for 2 units PRBC

\section{Wait 10 minutes}

\section{Bleeding persists}

1. Continue bimanual compression

2. Administer Drug 2

3. Call for Drug 3 (misoprostol) and tamponade balloon

\section{Wait 15 minutes}

\section{Bleeding persists}

1. Continue bimanual compression

2. Administer Drug 3 and place tamponade balloon

3. Prepare OR

\section{Wait 10 minutes}

Bleeding persists = exploratory laparotomy (compression sutures, uterine artery ligation, hysterectomy)

*If at any time EBL >2000cc, institute massive transfusion protocol (6-4-1). If at any time $\mathrm{BP}<80$ (s) or $<40$ (d) and/or pulse $>120 \mathrm{bpm}$ with continued bleeding, institute MTP and proceed with laparotomy

** EBL 1000 cc for cesarean delivery

Drug doses: misoprostol $600 \mathrm{mcg}$ PR, 15m PGF2 $\alpha 250 \mathrm{mcg}$ IM, methergine $0.2 \mathrm{mg}$ IM

Figure 1. Uterine atony checklist. 
Table 1. Clinical details of patients dying of uterine atony.

\begin{tabular}{|c|c|c|c|c|c|c|c|c|c|c|c|c|}
\hline & Case \#1 & Case \#2 & Case \#3 & Case \#4 & Case \#5 & $\begin{array}{c}\text { Case \#6 } \\
(2008)\end{array}$ & $\begin{array}{c}\text { Case \#7 } \\
(2000)\end{array}$ & $\begin{array}{c}\text { Case \#8 } \\
(2003)\end{array}$ & $\begin{array}{c}\text { Case \#9 } \\
(2007)\end{array}$ & $\begin{array}{c}\text { Case \#10 } \\
(2011)\end{array}$ & Mean & SD \\
\hline Time of Delivery & 0:00 & 0:00 & 0:00 & 0:00 & 0:00 & 0:00 & 0:00 & 0:00 & 0:00 & 0:00 & & \\
\hline Time at Diagnosis of Atony & $0: 39$ & $0: 19$ & $0: 41$ & $0: 33$ & $0: 23$ & $0: 10$ & $0: 22$ & $0: 40$ & 0:05 & $1: 00$ & & \\
\hline Time of Atony Rx \# 1 & $0: 39$ & $0: 19$ & $1: 11$ & $0: 33$ & $0: 23$ & $0: 20$ & $0: 32$ & $0: 50$ & 0:06 & $1: 25$ & & \\
\hline Time of Atony $\mathrm{Rx} \# 2$ & $0: 57$ & & 3:26 & 1:08 & $0: 27$ & $0: 35$ & $0: 37$ & $1: 10$ & & $3: 15$ & & \\
\hline Time of Atony $\mathrm{Rx} \# 3$ & $1: 18$ & & $5: 06$ & 2:01 & $0: 37$ & & $0: 52$ & & & & & \\
\hline Time of Exploratory Laparotomy & & & $1: 51$ & 3:53 & & $3: 50$ & $3: 02$ & $4: 10$ & $8: 00$ & & & \\
\hline Time pulse $>120 \mathrm{bpm}$ & 1:09 & $1: 04$ & $4: 11$ & $1: 38$ & $1: 13$ & $0: 35$ & $0: 32$ & & 2:00 & $5: 15$ & & \\
\hline Time of PRBC \#1 & $1: 59$ & $1: 39$ & $2: 26$ & 2:55 & $1: 57$ & $1: 20$ & $1: 22$ & $1: 40$ & 2:00 & $5: 18$ & & \\
\hline Time of Arrest & $3: 31$ & $3: 55$ & $5: 46$ & $6: 08$ & $4: 57$ & $2: 25$ & $1: 52$ & $3: 10$ & 13:00 & $8: 15$ & & \\
\hline Interval Atony $\mathrm{Dx}$ to $\mathrm{Rx} \# 1$ (min) & 0 & 0 & 30 & 0 & 0 & 10 & 10 & 10 & 1 & 25 & 8.6 & 11.0 \\
\hline Interval Atony Dx to PRBC \#1 (min) & 80 & 80 & 105 & 142 & 94 & 70 & 60 & 60 & 115 & 258 & 106.4 & 59.2 \\
\hline Interval Atony Dx to Ex Lap (min) & & & 70 & 200 & & 220 & 160 & 210 & 475 & & 222.5 & 135.3 \\
\hline Interval Atony to Pulse $>120 \mathrm{bpm}(\mathrm{min})$ & 20 & 45 & 200 & 65 & 50 & 25 & 10 & & 115 & 255 & 87.2 & 86.4 \\
\hline Interval Atony to Arrest (min) & 172 & 216 & 305 & 335 & 274 & 135 & 90 & 150 & 775 & 435 & 288.7 & 200.5 \\
\hline Interval Pulse $>120$ to Arrest (min) & 142 & 171 & 95 & 270 & 224 & 110 & 80 & & 660 & 180 & 214.7 & 177.9 \\
\hline
\end{tabular}

Formal exemption for IRB approval of this review was obtained from the Baylor College of Medicine Institutional Review Board.

As outlined in Table 1, the times from the diagnosis of atony to the administration of the first drug was not appreciably reduced with the protocol, although this was likely a product of our definition of atony onset described above. In 8 of 10 cases, application of this protocol would appear to have resulted in more timely administration of additional drugs. In the 6 cases in which laparotomy preceded cardiac arrest, protocol-directed laparotomy would have been initiated an average of 194 minutes earlier than the actual laparotomy. In 9 of 10 cases, a massive transfusion protocol would have been initiated based on pulse alone at least 30 minutes sooner than was any transfusion at all. This would have resulted in application of the massive transfusion protocol an average of 178 minutes prior to the cardiac arrest. In all 10 cases, application of this protocol would have resulted in abandonment of conservative management and application of a definitive surgical procedure before the time of actual cardiac arrest. In 9 of 10 cases, this would have occurred over an hour prior to cardiac arrest with a mean of $229 \mathrm{mi}$ nutes earlier [Table 1].

The differential diagnosis of postpartum hemorrhage is short and includes only uterine atony, retained placenta and its variants, upper and lower genital tract lacerations, 
uterine inversion, and occasional coagulopathy. It is of obvious importance to eliminate causes of postpartum hemorrhage other than uterine atony prior to utilization of this protocol. Generic treatment of non-specific "postpartum hemorrhage" without one of the specific diagnoses listed above is unwise [6]. This intensive and time-limited approach might be termed the active management of uterine atony. Our data suggest that application of this protocol would have resulted in more timely drug treatment, more robust transfusion therapy, and hysterectomy when necessary, well prior to cardiac arrest in the majority of women in our series who ultimately exsanguinated. Because of the limitations described above in our definition of the onset of atony, it is probable that the time frames outlined in Table 1 would have been shortened even more in actual clinical practice.

In the application of this protocol, several observations are germane. First, our focus in the development of this protocol was to address specific practice patterns that commonly result in avoidable maternal death, rather than providing a comprehensive treatise on the management of postpartum hemorrhage. Simplicity is one key to successful protocol or checklist development, and the clinical utility of any protocol is inversely related to its length, complexity, and the number of embedded arrows and dotted lines. We have therefore addressed the most common cause of avoidable maternal death from hemorrhage-lack of an intensive, focused approach to atony and perseverance with therapies that are not working [3] [5] [6]. This protocol encourages the methodical use of a defined sequence of medical therapies incorporating a time element at each step, followed when necessary by a definitive surgical approach.

Accordingly, this protocol does not address the details of obtaining venous access, the rapid marshalling of appropriate nursing and physician resources, transfusion therapy or eliminating anesthetic agents that interfere with myometrial contraction. The omission of these details does not in any way detract from the importance of such measures; rather, it simply reflects the fact that excellent protocols addressing these issues already exist [3] [4] [7] [8]. In a similar manner, we do not discuss technical details of specific surgical measures for dealing with uterine atony, which are well described in the literature. Such measures may include laparotomy, the B-Lynch suture, uterine artery ligation and hysterectomy [9]-[11]. While any of these measures may ultimately be appropriate and necessary for the definitive treatment of uterine atony, it is our experience that patients in whom any of these surgical procedures have been initiated prior to the onset of hypovolemic shock or cardiac arrest are generally in good hands, and survive. For the hemodynamically stable patient with very slow, ongoing hemorrhage, angiographic embolization may also be an option, but should not generally be used for acute, life-threatening bleeding with shock [12]. As emphasized repeatedly in the protocol, firm bimanual uterine compression is generally highly effective in slowing or stopping blood loss due to atony while both general and specific therapeutic measures are instituted.

The three drugs commonly utilized for treatment of uterine atony in the US are PGE 1 (misoprostol), 15 methyl PGF2 $\alpha$, and methergine [Figure 1]. While none of these 
agents has been shown to be clinically superior to the others, recent data suggest that simultaneous use of misoprostol with oxytocin is unlikely to have added benefit and thus either 15 methyl PGF2 $\alpha$ or methergine may be a better choice than misoprostol as a first line drug [13]. However, these drugs may be used in any order within the protocol. Similarly, balloon tamponade may be used prior to the time called for in this protocol and may be preferred in the presence of shock when effective peripheral absorption of any drug is unlikely [4] [14]-[16]. Regardless of the order in which these agents are used, implementation of this protocol at the first diagnosis of uterine atony will, in most cases, result in the administration of all of these drugs and placement of a balloon prior to the onset of shock as long as the cumulative timeline for non-surgical resolution of hemorrhage described in this protocol is not exceeded. Fundamental principles of patient safety and standardization dictate that clinicians utilizing this protocol establish a facility-specific order for drug administration and balloon placement, barring patient contraindications [17].

This checklist includes a flow sheet for formal and methodical documentation of elapsed time, estimated blood loss, blood pressure and pulse. We suggest that these factors be documented contemporaneously, similar to the procedure for documentation of Advanced Cardiac Life Support measures [18]. When specified parameters of blood loss, pulse or blood pressure are exceeded, our protocol calls for abandonment of medical management. Obviously, in special cases (such as patient refusal of transfusion) this time-line may also need to be shortened.

As with any properly developed and implemented treatment checklist, exceptions and variations from the protocol will at times be necessary. Such care is appropriate when an experienced clinician at the bedside identifies specific clinical features of an individual patient that suggest the need for variation, and can clearly articulate her/his rationale for such a decision in the medical record. Similarly, the time frames outlined for decision-making are intended as guidelines, which need not always be followed to the minute. In particular, we recognize the incredibly difficult nature of decisions regarding operative intervention in which the distinction between an unnecessary hysterectomy and an unnecessary death is narrow, and the ideal course of action may, even in retrospect be unknowable. We feel it difficult to justify post-hoc criticism of a concerned physician making difficult decisions at the patient's bedside, which may result in hysterectomy. The purpose of this checklist is to assist the clinician in making such decisions on a rational basis, not as an inviolable standard against which he/she should be judged.

Finally, this protocol might be criticized by the observation that additional drugs are often called for without allowing for sufficient time to unequivocally demonstrate complete lack of efficacy of the previously administered agents. While it is undoubtedly true that some patients may ultimately respond to any of these drugs given enough time (or that the problem may resolve with time alone), we believe that the hazards of ongoing hemorrhage do not justify additional delay "just in case" a drug might ultimately have an effect. If this protocol is followed, sufficient time will have elapsed prior to hyste- 
rectomy to justify a decision that medical therapy has proven ineffective. If atony resolves and then recurs, one might either resume the protocol at the point is was stopped, or start the drug sequence again while being mindful of cumulative blood loss.

We also remind the reader that this protocol is presented as a Clinical Opinion, and was derived from the available literature, basic science considerations, and our own extensive clinical experience. We include the data in Table 1 for illustrative purposes only and intend no inference that the protocol was or could be derived from these data, or that the data in any way prove that application of this protocol would have been life saving. While adherence to this protocol represents a reasonable and useful guide to medical care, it would be inappropriate to conclude that it in any way represents an exclusive standard, or that had this protocol been applied in an individual case, either morbidity or mortality would have been avoided.

Advances in obstetric care have resulted in significant improvements in mortality rates from infection, hypertensive disease and thromboembolism. While neither morbidity nor mortality from any of these causes has been eliminated, reducing mortality from postpartum hemorrhage remains an unresolved challenge. We feel that the development of a standardized and methodical approach incorporating a time element into each step of the medical management of uterine atony is imperative. Our medical critical care colleagues long ago abandoned the notion that undirected physician judgment should guide the provision of basic and advanced cardiac life support; such care is today directed by highly specific and uniform protocols [18]. Few physicians have sufficient personal experience with unresponsive, life-threatening hemorrhage to allow for the effective use of clinical judgment in these situations. Thus we feel that the management of severe postpartum atony deserves the same level of concern as does the provision of basic and advanced life support and that a similar specific, uniform approach is justified.

This protocol provides one such approach that can be tested, validated and modified by additional larger scale prospective studies examining not only death but also less dramatic endpoints such as blood loss, transfusion, and shock.

\section{References}

[1] Clark, S.L., Belfort, M.A., Dildy, G.A., et al. (2008) Maternal Death in the $21^{\text {st }}$ Century. Prevention and Relationship to Cesarean Delivery. American Journal of Obstetrics \& Gynecology, 199, 35e1-e5.

[2] Berg, C.J., Callaghan, W.M., Syverson, C. and Henderson, Z. (2010) Pregnancy-Related Mortality in the United States. 1998 to 2005. Obstetrics \& Gynecology, 116, 1302-1309. http://dx.doi.org/10.1097/AOG.0b013e3181fdfb11

[3] Clark, S.L., Christmas, J.T., Frye, D.R., et al. (2014) Maternal Mortality in the U.S.-Predictability and the Impact of Protocols on Fatal Post-Cesarean Pulmonary Embolism and Hypertension-Related Intracranial Hemorrhage. American Journal of Obstetrics \& Gynecology, 211, 32e1-e9.

[4] Lagrew, L.A., Shields, L., Main, E. and Cape, V. Improving Health Care Response to Obstetric Hemorrhage-California Maternal Quality Care Collaborative Toolkit. https://www.cmqcc.org/ob_hemorrhage 
[5] Howard, T.F. and Grobman, W.A. (2015) The Relationship between Timing of Postpartum Hemorrhage Interventions and Adverse Outcomes. American Journal of Obstetrics \& Gynecology, 213, 239.e1-e3. http://dx.doi.org/10.1016/j.ajog.2015.04.017

[6] Clark, S.L. and Hankins, G.D.V. (2012) Preventing Maternal Death-10 Clinical Diamonds. Obstetrics \& Gynecology, 119, 360-364. http://dx.doi.org/10.1097/AOG.0b013e3182411907

[7] American College of Obstetricians and Gynecologists Practice Bulletin \#76. Postpartum Hemorrhage.

[8] American College of Obstetricians and Gynecologists Patient Safety Checklists \#10. Postpartum Hemorrrhage from Vaginal Delivery.

[9] B-Lynch, C., Coker, A., Lawal, A.H., Abu, J. and Cowen, M.J. (1997) The B-Lynch Surgical Technique for the Control of Massive Postpartum Hemorrhage: An Alternative to Hysterectomy? British Journal of Obstetrics and Gynaecology, 104, 372-375.

http://dx.doi.org/10.1111/j.1471-0528.1997.tb11471.x

[10] O’Leary, J.L. and O’Leary, J.A. (1974) Uterine Artery Ligation for Control of Post-Cesarean Section Hemorrhage. Obstetrics \& Gynecology, 43, 849-853.

[11] Stanco, L.M., Schrimmer, D.B., Paul, R.H. and Mishell Jr., D.R. (1993) Emergency Peripartum Hysterectomy and Associated Risk Factors. American Journal of Obstetrics \& Gynecology, 168, 879-883. http://dx.doi.org/10.1016/S0002-9378(12)90838-8

[12] Hong, T.M., Tseng, H.S., Lee, R.C., Wang, J.H. and Change, C.Y. (2004) Uterine Artery Embolization: An Effective Treatment for Intractable Obstetric Hemorrhage. Clinical Radiology, 59, 96-101. http://dx.doi.org/10.1016/j.crad.2003.08.007

[13] Hofmeyer, G.J., Gulmezoglu, M., Novikova, N. and Lawrie, T.A. (2013) Postpartum Misoprostol for Preventing Maternal Mortality and Morbidity. Cochrane Database of Systematic Reviews, 7, Article ID: CD008982.

[14] Tindall, K., Garfinkel, R., Abu-Haydar, E. et al. (2012) Uterine Balloon Tamponade for the Treatment of Postpartum Hemorrhage in Resource-Poor Settings. A Systematic Review. British Journal of Obstetrics and Gynaecology. http://dx.doi.org/10.1111/j.1471-0528.2012.03454.x

[15] Dildy, G.A., Belfort, M.A., Adair, C.D., et al. (2014) Initial Experience with a Dual Balloon Catheter for the Management of Postpartum Hemorrhage. American Journal of Obstetrics \& Gynecology, 210, 136e1-e6.

[16] Bakri, Y.N., Amri, A. and Abdul Jabbar, F. (2001) Tamponde-Balloon for Obstetrical Bleeding. International Journal of Gynecology \& Obstetrics, 74, 139-142. http://dx.doi.org/10.1016/S0020-7292(01)00395-2

[17] Clark, S.L., Meyers, J.A., Frye, D.K. and Perlin, J.A. (2011) Patient Safety in Obstetrics: The Hospital Corporation of America Experience. American Journal of Obstetrics \& Gynecology, 204, 283-287. http://dx.doi.org/10.1016/j.ajog.2010.12.034

[18] Sinz, E. and Navarro, K., Eds. (2011) American Heart Association Advanced Cardiac Life Support Provider Manual. American Heart Association. 
Submit or recommend next manuscript to SCIRP and we will provide best service for you:

Accepting pre-submission inquiries through Email, Facebook, LinkedIn, Twitter, etc. A wide selection of journals (inclusive of 9 subjects, more than 200 journals)

Providing 24-hour high-quality service

User-friendly online submission system

Fair and swift peer-review system

Efficient typesetting and proofreading procedure

Display of the result of downloads and visits, as well as the number of cited articles

Maximum dissemination of your research work

Submit your manuscript at: http://papersubmission.scirp.org/

Or contact ojog@scirp.org 